Jan Völker*

\title{
Hegel's Entäußerung - Notes on the Kenotic Actualisation
}

\section{Beginning with an inhibition}

The preface to the Phenomenology of Spirit provides the reader with an instruction on how the pages that follow are not to be read. Hegel famously begins by rejecting the assumption that a preface might summarise the content that follows and might indicate in advance the aims of the book that follows. He rather insists on the contrary, namely that an apparent result does not exhaust the "real issue," and declares an indicated "aim" to be nothing but a "lifeless universal." The "real issue," on the contrary, is stated by "carrying it out" and the result is not only the entirety of the thought that has been carried out, but the entirety plus its development. ${ }^{2}$

The preface, which is, as the title says, "on scientific cognition," does immediately block our spontaneous understanding, according to which 'science' brings about and is summarised in 'results'. Furthermore regarding this blockage, we cannot expect that the preface might provide us with some information beforehand, that it might outline and condense the most important and central results or enumerate the most pressing aims of this complicated and long book that lies before us. Hegel refuses to give us that orientation which we expect from a preface, and we should be warned: that kind of orientation which gives us facts to follow will also not be handed in at some later point; we should rather expect a crisis of orientation as a result of the pages that follow.

If the preface is not the correct place for a summary, then any beginning or any final paragraph of a chapter will not be able to do so either. We have to anticipate that we will perhaps not find a single passage in the entire book that

1 G. W. F. Hegel, Phenomenology of Spirit, trans. A. V. Miller, Oxford University Press, Oxford 1977, p. 2.

2 Ibid., p. 2.

3 Ibid., p. 1.

Berlin University of the Arts 
would provide us with the safety of a brief summary, a point to rely on, and a starting point for an understanding to continue its work. Thus, we will have to go through the entire book, will have to read each single paragraph and page, and at the end we will have to make an attempt at understanding the totality of the thoughts and their development, which might have to fail. But if this attempt cannot lead to a result, which we might transmit or retain as knowledge - as in claims like "Hegel's basic thesis is...," - then into what are we being led?

An instruction on how a book is not to be read is not yet an instruction on how to read it. But, at the same time, this instruction seems dubious when its consequences are considered, and it makes us wonder if we do not perhaps have to read the text in the regular way, despite Hegel's insinuation of its impossibility. Who would stop reading at this point? Would we not have to say that our problematic is exaggerated, because even if Hegel refuses to summarise the content of his book into aims (and their realisations), is not a sort of summary always necessary in any single passage, in fact in every single sentence? Is not some kind of an aim always implied in the act of thinking and writing, even if Hegel does not want it to be this way? How could philosophy proceed if it were not one by one? And does not this necessity - to go one by one - imply the basic structure of aim, method, and result?

Of course, the direction we are aiming at can already be sensed, although we have not yet indicated it as such: it seems we are aiming at the question of speculation, which Hegel defines as overturning the linear causality of spontaneous thought. And our spontaneous reading continues as if it were evident that we will grasp the speculative content. But before we get to this result, we should emphasise a different problem, coming along with the declared impossibility to fixate aims and results. Not only is there a problem of how to continue reading, but before this there is a difficulty of beginning: in our spontaneous understanding, we would assume, at least, that every passage, every sentence can be understood as referring to something before its own beginning; every passage, every sentence carries something further and thus refers backwards and forwards. If we do not find a fixation of what is being said, a fixed meaning, then we are not given a point of departure, and consequently we have to understand that our reading will have to grasp a development without any beginning at all. No passage, no sentence will begin anew, and no passage, no sentence will provide an interruption, a summary, a stopping point. Everything has already 
begun before it began. But if there is no beginning, we might also argue that we cannot read anymore, for we are not able to move forwards or backwards within the text. There appears an impossibility to read along the lines of our usual customs and practices.

But, of course, this is not the entire story. As we actually do read the preface, we do follow the path marks of fixations, we follow along one sentence, in which we grasp a meaning, to the next. The difficulty of the beginning is not an actual difficulty, for we can simply read. We can be pragmatists. But in this case we might still not be out of trouble: we will have to realise, later, that the actualisation of this impossibility works against us, from the beginning on; it unfolds itself, all the while we are following Hegel's propositions, one by one. It is indeed what Hegel wants us to do, to walk stubbornly into this trap. For it is Hegel's point that the impossibility of our familiar forms of reading unfolds only if we read. This is famously described in the notion of the "speculative exposition,"/4 which Hegel contrasts with our usual approach to a regular proposition. The speculative, dialectical movement of a proposition, which consists of an "internal inhibition" and a "return of the essence into itself," cannot be found as an element of the regular phrase itself; it is neither its regular meaning, nor is it a signified content. ${ }^{5}$ Rather, it takes place as and in the movement of the proposition itself. And philosophy needs to present this movement and to enunciate it:

The sublation of the form of the proposition must not happen only in an immediate manner, through the mere content of the proposition. On the contrary, this opposite movement must find explicit expression [...]. This return of the Notion into itself must be set forth [presented, "dargestellt sein”, J.V.]. This movement which constitutes what formerly the proof was supposed to accomplish, is the dialectical movement of the proposition itself. This alone is the speculative in act, and only the expression [enunciation, “Aussprechen”, J.V.] of this movement is a speculative exposition [presentation, “Darstellung”, J.V.]. ${ }^{6}$

4 Ibid., p. 40.

5 Ibid.

6 Ibid., pp. 39-40. For the Cerman concepts, which I indicated in brackets, see Georg Wilhelm Friedrich Hegel, Phänomenologie des Geistes, Werke, Vol. 3, Frankfurt am Main 1986, p. 61. 
The immanent difficulty is that the "philosophical" exposition of the speculative movement will be irreducible to a regular proposition, although it needs to be enunciated. We will have to think and understand a different kind of enunciation. However, we see that we will find our way by reading one sentence after another, and it is in this very process that something else takes place, something that demands to be enunciated. Will we find it in the subsequent proposition? The concatenation of propositions continues in a regular way, but we cannot inscribe the speculative moment as the content into the proposition that follows.

Where we start, then, is a moment of deception, inhibition, disorientation. Something is going on, though, which tells us that our regular understanding is inhibited. But we are also inhibited from moving backwards, to a preceding proposition, as we are inhibited from moving forward. We are not only blocked in our reading, but we have entered a space of disorientation. Jean-Luc Nancy has linked this troubling structure of the preface to the structure of the Aufhebung, which seems to pave the way from the regular to the speculative proposition, but proves, as it were, to be presupposed and suspended at the same time. "Another grammar" is announced ${ }^{7}$, Nancy writes, but the transition from our usual grammar to the speculative grammar, the Aufhebung of the regular grammar, is missing, while it remains presupposed: what takes place within the proposition seems to refer to its conceptual presupposition, for then we would know how to read the speculative moment, but as it is not given, "presupposition" and "positing" become one. ${ }^{8}$ We read, but we have to read differently:

Dispossessed or unsettled in this manner, we will be reading, or be writing, nothing else but the gap [écart], the displacement that produces this disruption in Hegel's text - or, if you like, this alteration in the course of which the necessity of another grammar, of another proposition, is being proposed. We must, without any further warnings, since the entire system of warnings has just revealed itself to be useless, read these others, or this other, in Hegel, which is to say, of course, read Hegel otherwise, and finally, to come (back) to our 'object,' read or write otherwise the Aufhebung. ${ }^{9}$

7 Jean-Luc Nancy, The Speculative Remark (One of Hegel's Bons Mots), trans. Céline Surprenant, Stanford University Press, Stanford CA 2001, p. 17.

8 Ibid., p. 16.

9 Ibid., p. 19. 
To read otherwise is to write the trace of the sublation. The entire process refers back to the necessary presentation of the speculative moment - the Darstellung which cannot be considered as given as a propositional content, but becomes rather a "matter of grasping," as Nancy puts it with reference to the German 'fassen, ${ }^{10}$ Reading/writing is a process of "plasticity," ${ }^{11}$ and thus it entails a moment that is not purely reducible to a juxtaposition of operations, but is a moment of something taking place within the text, within us, reading it. The presentation is actually an actualisation that defines a constellation of time and space, including the reader and the text, but building up beyond them. The "speculative in $a c t,{ }^{12}$ and the need to enunciate it, lead us to a "voice," Nancy adds a little later, but it is neither Hegel's voice nor our voice as readers, but a voice in which "it speaks [ça parle]." ${ }^{{ }_{13}}$ Reading, writing, speaking, hearing: each of the moments is marked by a deferral; we read the other in Hegel, and thus write, but write a movement, not a proposition, and also hear the enunciation of the speculative, but surely not with our ear; neither do we hear it as a speaking voice.

The presentation becomes a scene: but in this scene we find two parties involved. The other, which speaks, and another, in which, through which, it is enunciated. Thus, we will ask whether this voice finds an embodiment outside of the plain text. The voice needs to enunciate itself, but it can only do so by passing through another in which, through which, it is embodied and again dispossessed. The voice would thus enunciate itself only by transcending itself and becoming an other. On the propositional level, we might assume that this voice must be Hegel's, but it can only make itself heard by passing through our reading body. But let us assume something else: it is the voice of the text, which needs to be written, and actualises itself by reappearing as the voice of a different text. Does reading Hegel demand to be written? And if so: What could be the methodological model for such a self-transcending actualisation? There is one candidate that we would like to propose here, namely the model of kenosis. Kenosis, meaning literally a process of self-emptying, describes Jesus' letting go of the divine attributes and becoming a human being, as well as becoming receptive to God's will. What we have in mind for the Hegelian scripture is a

\footnotetext{
$10 \quad$ Ibid., p. 12.

${ }_{11} \quad$ Ibid., p. 15.

12 Hegel, Phenomenology, p. 40.

13 Nancy, Speculative Remark, p. 33.
} 
radically secularised transposition of kenosis as self-emptying: Hegel's texture as voiding itself and externalising itself in different textual bodies. Let us, as a preliminary attempt, develop the outlines of such a model.

\section{Disappearances and their appearances}

To take up the thread of the preface again, and to link it in another manner to the appearing voice, we can say that, in order for the speculative to arise, not only does the propositional content have to cede its place, but the speculative voice can also only arise once we do not take it simply to be Hegel's voice. What is happening here cannot simply be referred back to the physical appearance of Hegel; rather, something else is taking place. Even though we might argue with Hegel that it is rather spirit that unfolds itself by means of philosophy, the book is nevertheless a physical entity, drafted, written, published by an author who is also present as an arguing, explaining, questioning voice within the text. However, this does not imply that Hegel is present in the book at any moment. What should be recognised is rather how Hegel prepares an appearance, then an organised disappearance of this author from within the text. We begin with an absent author: the inhibition to move backwards from within the propositional content crosses out the figure of the author. What we will have to watch out for is the moment of his appearance.

But let us go back to the text. So, even if Hegel has not yet appeared, we can at least figure out what he wants, for he does not hesitate to announce what cannot be called but the aim of the pages that follow: namely, to bring about the Darstellung, the presentation. This is stated right at the beginning of the preface, only that at this moment, at the beginning, we would not yet know what this is meant to be in a proper sense: "To judge a thing that has substance and solid worth is quite easy, to comprehend it is much harder, and to blend judgement and comprehension in a definitive description is the hardest thing of all." ${ }_{14}$ Therefore, we have to stick to "the real issue," ${ }_{15}$ der "Sache," ${ }_{16}$ and we have to stick to it even against the apparent "specific difference" of the thing, which is

\footnotetext{
${ }_{14}$ Hegel, Phenomenology, p. 3.

${ }_{15}$ Ibid., p. 3.

16 Hegel, Phänomenologie des Geistes, p. 13.
} 
only its "limit" ("Grenze"). ${ }^{17}$ We have to stick to the thing, not only judge it, but also grasp it ("es zu fassen"), and then the "most difficult of all is" to unite both and unfold its exposition. ${ }^{18}$

It is thus clear that before we know exactly what to make of the 'grasp', the exposition is the critical point, because, as we know from our previous discussion, this presentation excludes any meta-language in terms of aims, results, or summaries. We might also say that the presentation has to fall in line with the aims, results, and summaries of its own process. In this sense, as a form of its content, the presentation becomes totalised. Darstellung is not an unregulated presentation, not some - however regulated - imitation; rather, Darstellung leads us to the question of the system. Hegel addresses the 'Sache' that needs presentation, relatively quickly and directly, as "truth," 19 which can only be given within a scientific system.

At this point, we get into the first internal circuit or the first internal loop, for Hegel - we keep 'Hegel' as a name, which will need explanation at a later point now distinguishes his endeavour from the endeavours of the thought around him. He assumes that the attempt to understand the concept as the "true shape of truth" ${ }^{20}$ sets him in opposition to the current streams of philosophy. Two moments form these currents of philosophy, one is the will to expose the absolute according to the "wealth of material and intelligibility," ${ }^{21}$ while the other one is the formalist abyss of the "night in which all cows are black." ${ }^{22}$ Some lines before Hegel criticised an understanding of the "absolute" as something to "be felt and intuited," ${ }^{23}$ so that we can infer intuition and feeling on one side, and formalism on the other: Scylla and Charybdis, between which it is the task of the philosopher to keep a grip on the thing. It is especially the tendency towards the absolute as an intuition and a feeling that is an expression of a spirit which has

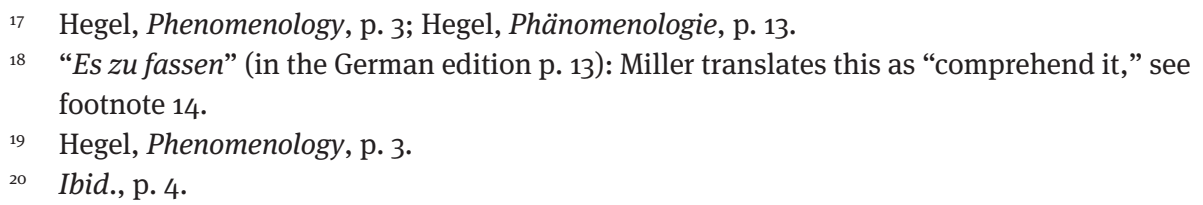


lost its essence. But in the formalist abyss it is not different - something is lost in the current of philosophy.

"Besides," Hegel argues, "it is not difficult to see that our own epoch is a time of birth and a transition to a new period." ${ }^{24}$ He understands his time to be a time of change, a time in which the spirit is about to change. The announcement of a change is the announcement that something new begins, it is the announcement of a new beginning. From this point on we might be able to shed some light on the question of the beginning. But we might also be able to gather some evidence about Hegel's role, his disappearance and appearance, as it is clear, although only rhetorically at this point, that the new beginning will not be without Hegel and his philosophy. The novelty of 'our' time is announced in the midst of the critique of the current forms of philosophy, their enjoyment of abstraction or their limitation to the realm of experience, and thus the new time could be understood to come with a new philosophy. It is difficult not to hear this voice.

However, Hegel takes a different approach, again. He declares that the new begins with an immediate moment, the new begins with the immediacy of a concept.

But this new world is no more a complete actuality than is a new-born child; it is essential to bear this in mind. It comes on the scene for the first time in its immediacy or its Notion. [...] The onset of the new spirit is the product of a widespread upheaval in various forms of culture, the prize at the end of a complicated, tortuous path and of just as variegated and strenuous an effort. It is the whole which, having traversed its content in time and space, has returned into itself, and is the resultant simple Notion of the whole. ${ }^{25}$

Thus, it is the concept where the new begins - the concept into which everything that has been has returned. The concept summarises, condenses, and integrates everything that has been into its form. These two moments have to be taken together: the concept summarises the shapes of the "various forms of culture," but as such, as a summarising notion, it does also mark the beginning of something new. This concept, which returns to itself in the process of its unfolding,

\footnotetext{
24 Ibid., p. 6.

25 Ibid., p. 7 .
} 
marks the point at which change begins. The change begins with a concept that is rich and vast, as it comprises the past, but in its appearance this concept is like a "flash," it strikes us within a single moment. "The gradual crumbling that left unaltered the face of the whole is cut short by a sunburst which, in one flash, illuminates the features of the new world." ${ }^{26}$ We might also say that the presentation, the Darstellung, which is given by the concept - its form - changes its own vast and rich content into something new.

We are reminded of our trouble from the beginning. The change which Hegel announces is a change that does not begin by opening something new in a strict sense, but rather by giving a form to the things that have been happening, to the past. Of course, Hegel does not mention the novelty as such, he only speaks of a transition. But even if change does not refer to the radical outbreak of something new, a transition implies a change, and a change implies the question of novelty, or at least the question of a significant difference.

Once again we are dealing with something that has already begun, and the change that occurs is not a change inflicted by something new, but the change has begun with the contraction of the old for itself. The view backwards marks the beginning of a view forward: but the form of the concept, which hits us like a flash, is, however, only a moment of the transition; it is, we could say, only a beginning of a beginning, but has not yet gained its full actuality. The transition consists of something old coming to be for itself in a concept, which has not yet unfolded itself completely, and thus, the concept, the turning point has no beginning and no end, no point to pin down that something new has arrived, and thus no real point to be declared, no point of declaration. But - to reread Hegel's remark: "Besides, it is not difficult to see that our own epoch is a time of birth and a transition to a new period." ${ }^{27}$ Now we can see that this remark in all its rhetorical casualness - "besides" - is a moment of the appearance of Hegel, whom we have to suspect to be the point of decision within the concept. Maybe Hegel is just the point within the concept - and the concept at stake here is the concept of science - the point at which the transition is marked by an inner difference that distinguishes the old from the new. The turn of the times, a turn

\footnotetext{
26 Ibid.

${ }_{27}$ Ibid., p. 6.
} 
towards science, unfolds its movement through the body of Hegel, and Hegel's body speaks.

Let us take a look at the 'thing' again. Opposed to the current streams in distinction from which Hegel situates his own project, he claims that "everything turns on grasping and expressing the True, not only as Substance, but equally as Subject." ${ }^{28}$ A "living substance," ${ }^{29}$ Hegel explains, is one in which negativity is inscribed. The inscription of negativity is not only the inscription of difference, but as the inscription of difference, it is also the negation of this symmetrical relation between difference and its other; thus, it is not only difference, but also a "self-restoring sameness," ${ }^{30}$ a living substance is different and indifferent at the same time. It is here that Hegel comes back to the aim and to the result: "[...] the True [...] is the process of its own becoming, the circle that presupposes its end as its goal, having its end also as its beginning; and only by being worked out to its end, is it actual." ${ }^{31}$ And further: "Of the Absolute it must be said that it is essentially a result, that only in the end is it what it truly is; and that precisely in this consists its nature, viz. to be actual, subject, the spontaneous becoming of itself." ${ }^{2}$

And of course, Hegel is aware that we might have understood him differently at the beginning, and he immediately admits that "it may seem contradictory" to understand the absolute as a result, and we might add that it is also difficult to understand why a specified aim which he rejected at the beginning is now explicitly posited as the very beginning. ${ }^{33}$ However, Hegel argues, the beginning, "as at first immediately enunciated" is "only the universal," and uttering a universal point of beginning does not at all exhaust its content. ${ }^{34}$ But this beginning is necessary: we need a point of beginning, a concept; and even more, the beginning is a single word such as, for example, 'the absolute'. Only such a single word can express the immediate beginning: "Whatever is more than such a word, even the transition to a mere proposition, contains a becoming-other

\footnotetext{
Ibid., p. 10.

Ibid.

Ibid.

Ibid.

Ibid., p. 11.

Ibid.

34 Ibid.
} 
that has to be taken back, or is a mediation." 35 We begin with a purpose, and have to follow its unfolding; the "realized purpose" is the self as "unrest" and becoming, which by its development unfolds itself as a self and returns to itself as an immediate beginning, and thus falls into "rest," it is itself. ${ }^{6}$ The self is rest and unrest. But rest by itself, as we have seen, is a difficult thing to achieve. It can only be rest as the unrest that remains with itself, "tarrying with the negative," says Hegel, "is the magical power." ${ }^{37}$ Hegel has appeared, and he does not appear as the limit between the old and the new; rather, he appears within the concept as its inner split, and he externalises this split to the external form of a split between the old and the new.

Hegel tells us that the method for establishing this circle is speculative thinking. And it is in the same preface that we find an explanation of not only speculative thinking, but precisely of how to read speculative thinking. He says it very explicitly: "What, therefore, is important in the study of Science, is that one should take on oneself the strenuous effort of the Notion." ${ }^{8} 8$ What we have to read is the concept, and we have to read it from the beginning. But the concept is the interruption of representational thought. What philosophy will have to give us, then, what Hegel will have to give us, is the concept. To understand Hegel's insistence on the concept in this context, we need to follow the comparison he builds up between "speculative thought," 39 which is the translation of "begreifende[s] Denken," comprehending thought, and something that is translated as "ratiocinative thinking," 40 and which in German is the "räsonnierende Denken." ${ }^{\prime \prime 1}$ To simplify things, we may allow ourselves to understand comprehending thought as speculative thought, as the translation suggests, and we will abbreviate "ratiocinative thinking" as representational thought.

In the latter then - in representational thought - we find the presupposition of a subject: representational thought negates or affirms a thing. It either says this is nothing, and then the negation is a moment not of the thing, but of the "empty
Ibid.
Ibid., p. 12.
Ibid., p. 19.
Ibid., p. 35.
Ibid., p. 36.
Ibid.
Hegel, Phänomenologie, p. 57. 
' $\mathrm{I}$ '" that negates the thing.42 Or it affirms something, and then the argument posits a subject and relates the predicates to it. Either, or: a subject is presupposed, and the actual thing or no-thing depends on the subject. Speculative thought operates differently: here, the concept incorporates the negativity and "presents itself as the coming-to-be of the object."'3 In the movement of the concept, we again find an interplay of unrest and rest.

"In this movement the passive Subject itself perishes; it enters into the differences and the content, and constitutes the determinateness, i.e. the differentiated content and its movement, instead of remaining inertly over against it." ${ }^{44}$

One has to be careful here not to read too fast. It is the motionless subject of representational thought that breaks down and is now integrated into distinctions and into the content. At this point, Hegel has already carried out what he will subsequently explain: speculative thought is not opposed to representational thought, but the former takes place within the latter. How then does speculation operate within representational thought? Something happens to representational thought, and this event is even twofold. At first, rest turns into unrest, or is even overcome by unrest. Where there was a motionless subject, i.e. the empty I or the subject of a proposition, we now receive a concept that is in motion and connects the former subject with the former content into one form. But then, second, a certain movement of representational thought is stopped and finds itself limited. While representational thought was free to pass from one predicate to the other and from one content to the other, the content is now bound to the self; it is only the content of this self. What was treated as a general predicate by representational thinking becomes a moment of the concept for speculative thinking. And when representational thought takes the liberty of going beyond the thing, by negating predicates or moving on to another content by means of the same predicates, this continuous progression along the chain of predicates is "checked in its progress," once the predicate has turned into a moment of the substance. ${ }^{45}$ It is within the proposition of representational thought that thinking receives a "counter-thrust. ${ }^{{ }^{4} 6}$ The subject, supposedly immobile, finds itself

\footnotetext{
42 Hegel, Phenomenology, p. 36.

43 Ibid., p. 37.

44 Ibid.

45 Ibid.

46 Ibid.
} 
sublated in the predicate; and now, as the predicate has become the "whole and the independent mass," thinking is "impeded by this weight" and stops moving freely. ${ }^{47}$ Hegel concludes:

Formally, what has been said can be expressed thus: the general nature of the judgement or proposition, which involves the distinction of Subject and Predicate, is destroyed by the speculative proposition, and the proposition of identity which the former becomes contains the counter-thrust against that subject-predicate relationship..$^{8}$

We might want to pause here once more, since we have been going through the circle a second time. And even if we recall that we are not allowed to pause, or rather that a pause is a kind of illusion, we nevertheless stumble about this summary, which irritates, impedes our reading simply by the attempt to "formally" express "what has been said."

We might, first of all, understand this sentence as an expression of the appearance of speculative thought. Speculative thought appears within thought, and it appears as the consequence of an inner blockage, produced by the movement of the sentence itself. It is representational thinking itself that provokes the appearance of speculative thinking. Nothing seems too difficult about this formal reconstruction. Speculative thought appears, and it is a body of weight that blocks the superficial sliding of representational thought. We might even understand that with the appearance of speculative thought we recognise the volatility of representational thinking, which runs along the predicates, shifts from one content to another, without ever changing its own form. Representational thinking is a technique involving the disappearance of thought, while speculative thought fosters the appearance of thought.

But we should distrust our understanding and be on guard. Where precisely does speculative thought appear? If it is brought about by the counterpunch, what is the body of speculative thought? What is the materiality of this crash? Once again, it seems to suggest itself that speculative thought appears in the process of reading. 'Reading' names the movement of the sentence as a real-

\footnotetext{
47 Ibid.

48 Ibid., p. 38.
} 
ised movement, and thus if there is an appearance of speculative thought, it appears in the movement of reading, which finds itself impeded - formally - in its process. We read and stumble, we speculate. But this is only a prelude to the problem. If the appearance of speculative thought can be expressed formally, and if it can be done in such a manner that speculative thought appears as an interruption of this formal sentence, then it might not be necessary to write speculative philosophy: the speculative might be a potential of the proposition itself. Is not any - regular - proposition formed by the combination of a subject and a predicate?

But on the contrary, Hegel seems to understand the philosophical proposition to be a proposition of a singular speculative weight at which the study of science aims, and this aggravates the difficulty, for the speculative moment cannot be referred to the reading of a sentence alone. Something is there, materially. Once the speculative impact of a sentence is linked to philosophy, something else comes into play. This something else might be called 'writing', but then again 'writing' might be an imprecise metaphor; at least it opens the door to a series of questions: Who is writing, what is being written, and how something is written that may or may not be read?

What appears above all on the scene is again Hegel. We are no longer talking about the speculative moment in general; rather, we are talking about the speculation within a philosophy signed by Hegel. Hegel refers speculation to philosophy, but nevertheless addresses the reader: the indicated turmoil of the speculative moment within a sentence might be the reason, he says, why philosophy is often considered incomprehensible. ${ }^{49}$ But now, once the speculative proposition is taken as a philosophical proposition, it all of a sudden turns into something other than what we thought before, when we understood the speculative as a quality of the proposition as such. The relation in which we find the speculative emerge is no longer the relation of the representational proposition to itself, its body is altered.

The "philosophical proposition," Hegel writes, is first of all a proposition, a grammatically ordered proposition. The "usual attitude" of the reader follows

49 See ibid., p. 39. 
the sentence in reading it and proceeds as it is used to..$^{50}$ "But the philosophical content destroys this attitude and this opinion." ${ }^{11}$ No longer is it about the speculative proposition impeding the grammatical structure of the sentence, but it is rather philosophy impeding the opinion, and presumably it is also about philosophy held down by the flux of the opinion. Held down by the eyes of the reader: the disoriented opinion of the reader is led to the experience that the meaning has to be something else. "[A]nd this correction of our meaning," Hegel concludes, "compels our knowing to go back to the proposition, and understand it in some other way." ${ }^{2}$

Philosophy is the moment in which the speculative concept appears, and before we get back to Hegel as the site of this appearance, we might have him disappear for a moment. However, we have to move further, for we stumble over this moment, in which we read that the speculative concept can be grasped in some other way. We stumble, we could say, because we had understood that the speculative moment appears when the representative sentence is impeded, and now the speculative moment, as a philosophical moment, can be grasped, even formally be grasped. For this reason, we have to take a look at that which is grasped, namely the concept.

The concept, as we saw, presents the coming-to-be of the object, or put differently, the object's becoming. In its specific formation, the concept will find its place within the unfolding of spirit. "With this, the Phenomenology of Spirit is concluded. What Spirit prepares for itself in it, is the element of [true] knowing. In this element the moments of Spirit now spread themselves out in that form of simplicity which knows its object as its own self., ${ }_{53}$

We see that the true concept expresses a form of the 'reconciliation' of the knowledge of itself with the knowledge of the thing, or in other words, the true concept expresses a form of the reconciliation of the self-consciousness with its consciousness. This is the story of a long development. The precarious moment at which we have to take a look is the moment at which the self-con-

\footnotetext{
50 Ibid.

51 Ibid.

52 Ibid.

53 Ibid., pp. 21-22.
} 
sciousness already knows that the knowledge of the thing is its own knowledge. The self-consciousness has understood that the consciousness of something is brought about by itself, but it still treats this knowledge of itself as if it were the knowledge of something. Here we find, so to speak, the last attempt to keep speculation under the flux of opinion. The concept has already taken in its own movement, but still treats it as if it were possible to understand itself by means of a regular phrase, as a subject that has its predicate.

This specific form of the concept, Hegel argues, disappears, dissolves, but it disappears in again another specific form, in which it turns to become the true concept. The distinction between the "determinateness" and the "fulfilment" of the concept vanishes, and it turns into a concept that "has attained it realization." 54 This overcoming of the distinction between the two sides of the concept develops into two different forms: on the one hand, it is realised in the spirit as "the self-assured Spirit that acted," and on the other hand it is realised in the spirit in the form of religion. 55 What we receive, in the end, is a concept in which its determination and fulfilment are intrinsically linked, and we find this in two shapes of spirit - the active and the religious spirit.

The moment of the active spirit, which possesses the active concept, will be unfolded in the book we are going to read as an apprenticeship novel, in which the spirit passes through the ethical world, alienation, enlightenment, and finally freedom and terror as its final diremption. In religion then, on the other hand, spirit appears as inactive, as a form of a not-actual, pure knowledge of the essence. In religion, Hegel argues in the final chapter of the Phenomenology, on the absolute knowing, spirit "won for consciousness the absolute content as content or, in the form of picture-thinking, the form of otherness for consciousness." "P6 "Picture-thinking" is the translation of "Vorstellung"57, but the explanation of it being "otherness for consciousness" makes it clear that what we are talking about is representational thought. If we allow ourselves to cause a short circuit, we see that representational thinking and its proposition, which is to some extent the regular proposition, has necessarily something religious

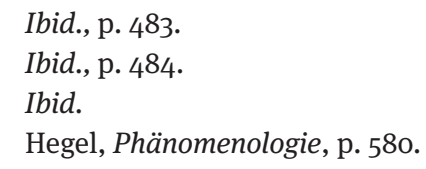


about it. And philosophy, as the coming-to-be of speculation, operates on and in, destroys, and impedes the religious proposition. But we will come back to this, once Hegel reappears.

But before that, let us outline the last step of the development of the concept. "This last shape of the spirit [...] this is absolute knowing"58 - content understood in the form of the self, thus realising the concept and remaining within the confines of the concept. Absolute knowing is the appearance of spirit in the form of science - science that exhibits the becoming of the concept. At this moment, once the development of the concept has come to an end, and has, in science, found itself as the content of its own form, the concept appears in a paradoxical way. The concept does appear, but it disappears at the same time. The concept appears in the form of science only after the representational thought of religion has been overcome.

The science of the concept has a specific point of its appearance "in time and in the actual world," it only comes to be once spirit gains "this consciousness about itself." ${ }^{9}$ But the unfolding of the concept in time is twofold, or split: it is a timely and spatial unfolding of something non-temporal, of something that withdraws from time and space. As the timely and spatial unfolding, the science has not only a specific moment in the time and space in which it comes to be, but it also has a prehistory. It is the substance of the concept, which exists beforehand, before it gains itself. In actuality, the substance of the concept is already given, before the concept comes to its own actuality or to its full existence. But as this substance is the concept which unfolds itself, as the concept is the knowledge of its own becoming in time, Hegel can draw the following conclusion: "Time is the Notion itself that is there and which presents itself to consciousness as empty intuition [...]."”o

Time is the concept, insofar as the concept unfolds itself in time; it is a stretch in time, which begins its development as the one-sided concept in itself, existing already as the substance, and unfolding itself in the knowledge of itself, thus returning to itself, getting to know itself. The concept is time as an actual circle,

\footnotetext{
58 Hegel, Phenomenology, p. 485.

59 Ibid., p. 486.

60 Ibid., p. 487.
} 
returning to its own beginning and grasping this beginning as its essence. But the concept is not only time, time is also, one could say, a concept: it is represented, as Hegel says, to consciousness as empty intuition, but the non-temporal aspect of the concept becomes clearer in the continuation of the quote. Hegel continues: “[...] for this reason, Spirit necessarily appears in Time, and it appears in Time just so long as it has not grasped its pure Notion, i.e. has not annulled Time." ${ }^{1}$

The pure concept, appearing in time and space, annuls time; it makes time disappear. It does not only represent time in some kind of analytic fashion, deprived of any spatial and temporal conditions, but it also actively annuls time. The concept appears in time and as such, and within time and space, it actively causes time to disappear. The concept is time: the concept is the appearance of time as its own disappearance. Maybe we should even go so far and also follow the implication that it is not only time that annuls itself, but also the concept, as the concept is time - the concept appears as its own disappearance. What we are left with, then, is the pure appearance of a disappearance. If Hegel is the body through which the concept speaks, he also disappears with the concept.

\section{Kenosis}

How can we understand this organised disappearance, which is an appearance as disappearance? Some pages later in the chapter on absolute knowing, to which we have jumped, Hegel reminds us that spirit is neither the pure inwardness of the self-consciousness, nor immersion into the substance. Rather, he says, "Spirit is this movement of the Self which empties itself of itself and sinks itself into its substance, and also, as Subject, has gone out of that substance into itself, making the substance into an object and a content at the same time as it cancels this difference between objectivity and content." ${ }^{62}$ It is, in other words, a movement that emerges between the one and the other, but as a movement it has already overcome the opposition between immersion and self-emptying. Spirit empties itself out and immerses itself in this way into the substance, and spirit goes from substance to subject by way of self-emptying. Thus, it comes back to itself only as a difference, in a doubled movement. Therefore, as spirit returns to

\footnotetext{
61 Ibid., p. 487.

62 Ibid., p. 490.
} 
itself with a difference, the actual movement of spirit is not the immersion, but it is the result of the movement of its own self-emptying: "[...] the power of Spirit lies rather in remaining the selfsame Spirit in its externalisation [...]."\%3

The German term for 'externalisation' here is "Entäußerung"64, and at this point we should take a look at this peculiar notion. In German, Entäußerung is linked to the Äußerung, the enunciation, and therewith cannot be separated from language and its specific movement to bring something onto the outside. But what is more, Hegel uses the word Entäußerung, which is Luther's translation of the word kenosis in the letter of Paul to the Philippians. We might assume that Hegel is aware of this, as he uses the term several times in the description of God becoming man in the body of His Son. ${ }^{65}$

But instead of sliding into this theological abyss, let us only emphasise that the self-emptying of the spirit, the self-emptying as its actual force, needs to be seen in a different light. Science, which comes to be at a specific point in time and space, is the form of spirit that remains "selfsame in its self-emptying," as Hegel said. Spirit, then, in the form of science, is a shape that remains selfsame within its own movement of self-emptying. The singular point, which we might emphasise here, is that in the Phenomenology the notion of the Entäußerung is not that clearly detached from the theological notion of the kenosis as it might seem. For we should not forget that spirit, in the shape of science, follows on what has already been there in the form of religion. In the form of religion, spirit is already there, as a content, or put differently, in the form of representational thinking. Spirit, in the shape of the science of the concept, is nothing but the kenosis of what has already been there in its substance, namely spirit in the form of religion. In this lineage, it would be better to understand Entäußerung as self-emptying, as Dubilet proposes, following Pinkert. ${ }^{66}$

63 Ibid.

64 Hegel, Phänomenologie, p. 588.

65 For the instances in which Hegel refers directly or indirectly to kenosis, as well as for a different and important take on this question, see Alex Dubilet, The Self-Emptying Subject, Kenosis and Immanence, Medieval to Modern, Fordham University Press, New York, NY 2018, pp. 92-147, here especially pp. $96-97$.

66 See ibid., p. 96. 
There are two elements to be found in the process of Entäußerung: the element of externalisation, turning something inside out, and the moment of letting go, changing and becoming other by letting go. Spirit changes by letting itself go and thus turning into the site of its own change, but spirit also externalises itself: as we saw, spirit unfolds its change in time and space. Finally, spirit enunciates itself, if we add the third implication of the Entäußerung.

Let us return to the appearance of Hegel, regarding whom we have seen how he disappears: within the concept that annuls time, also Hegel has to disappear. The science of the concept reaches beyond the book, it reaches beyond the phenomenal actuality of the Phenomenology, and within the concept the development of the concept comes to its annulation. Let us return to Hegel at the beginning of the book, to the Hegel who has not yet appeared, and of whom we only know that he will disappear. And let us return then to the proposition and its speculative moment, which unfolds itself within a proposition, because the usual opinion finds itself impeded in its attempt to understand the sentence. We saw that Hegel understands the speculative proposition to be a proposition of philosophy. Hegel admits that the speculative moment cannot take place solely within the proposition itself, in an immediate form, but it needs to be enunciated, geäußert: But this voice, as the voice in which it speaks, what is it other than an externalisation? And is not this voice the sound of the letting go of the regular proposition? Philosophy, then, does not express the speculative as if it were a content that could be expressed in a regular way, but philosophy creates a site at which the speculative can find its voice - which is nothing other than the externalised realisation of spirit's change.

Hegel presents himself as the one capable of creating a site for the expression of the speculative moment of thought, and thus we would by now not only have a definition of philosophy, but also a description of Hegel's role within philosophy. The master of the site. However, any moment of the construction, of the development of spirit, will in the end be sublated within the absolute knowing, and the absolute knowing, once it appears, eradicates any form of a general description of how a certain content would have to be treated. This is to say, as the split of the concept, Hegel is a disappearing master.

An obvious problem arises here, which is taken into account by Hegel himself. The problem is: Is not any presentation of the speculative moment a presentation 
that will rely on sentences in which we will find a subject and a predicate? Does not philosophy always disappear under the flux of regular propositions? In the preface, Hegel at first refutes the case of "the ordinary proof," in which any reason or proof given demands a further proof of this proof. ${ }^{67}$ In opposition to this, the speculative proposition, Hegel argues, is of a completely different nature.

As regards the dialectical movement itself, its element is the one Notion; it thus has a content which is, in its own self, Subject through and through. Thus no content occurs which functions as an underlying subject, nor receives its meaning as a predicate; the proposition as it stands is merely an empty form. ${ }^{68}$

But this inscription of the speculative moment into the site of the concept does not give us an answer to the original question, namely how the speculative moment of the proposition can be presented in such a manner that it does not again disappear within the regular norms of regular propositions. The speculative difference seems to disappear, and again Hegel appears. At the dangerous moment in which the entire speculative project risks breaking apart, Hegel appears. But how? First of all, we have to see that, in a strict sense, there cannot be an answer to this question. If the speculative moment appears within ordinary propositions or in ordinary thought and needs a presentation, for it would otherwise be indistinguishable, the question has to be whether it is possible to give a presentation to this difference by the use of ordinary propositions. And as necessary and legitimate this question is, there cannot be an answer thereto. For the answer is in itself speculative, and it cannot be given within a formula, it cannot be written within the logic of the ordinary proposition. However, it seems we have somehow been able to read it, at least we attempted to think about it. Where did we read it? What did we read? - We read Hegel. And this is the reappearance. It is here that Hegel reappears: at the moment in which the speculative proves to be elusive, Hegel is the form in which it is bound and finds its site. Hegel is the speculative moment.

But 'Hegel' then is no longer the name of an author. Rather, Hegel's philosophy appears in space and time, and although the site of the speculative moment is found in Hegel, Hegel is what is externalised, enunciated. Not simply within

${ }_{67}$ Hegel, Phenomenology, p. 40.

68 Ibid., p. 40. 
us, as readers, but rather in other written and dispossessed forms, forms that apply Hegel to itself, in space and time. But as they do so, they externalise Hegel and foster Hegel's self-emptying, and thus actualise the concept of science and annul the time in which it develops. They write and are Hegel's kenosis. Marx, for example.

\section{References}

Hegel, Georg Wilhelm Friedrich, Phänomenologie des Geistes, Werke, Vol. 3, Suhrkamp, Frankfurt am Main 1986

- Phenomenology of Spirit, trans. A. V. Miller, Oxford University Press, Oxford 1977

Dubilet, Alex, The Self-Emptying Subject, Kenosis and Immanence, Medieval to Modern, Fordham University Press, New York, NY 2018

Nancy, Jean-Luc, The Speculative Remark (One of Hegel's Bons Mots), trans. Céline Surprenant, Stanford University Press, Stanford, CA 2001 